\title{
La mirada de Alejandro Amenábar sobre un enemigo acérrimo: ¿la reconciliación del cine con Miguel de Unamuno?
}

\author{
Javier González Torres | javier.gonzalez@fundacionvictoria.edu.es \\ Fundación Victoria, Universidad de Málaga
}

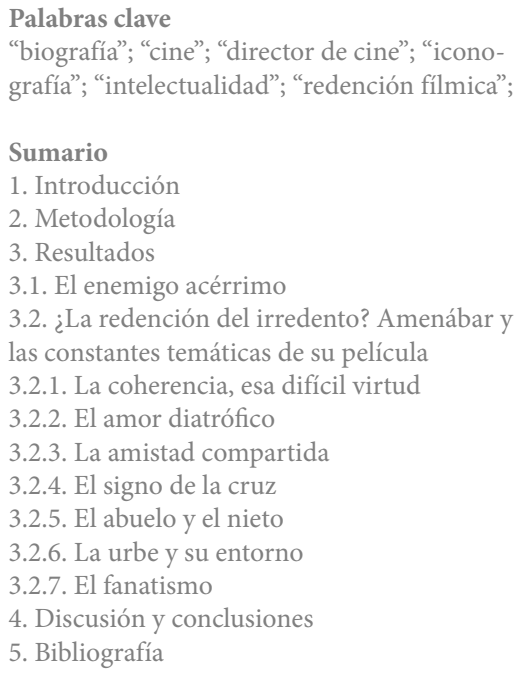

\section{Resumen}

Miguel de Unamuno es un 'agitador de espíritus'. Así se autodefine uno de los intelectuales más significativos de la historia contemporánea española. En su opinión libre, apasionada y políticamente incorrecta se advierte la subjetividad de quien observa los múltiples factores que impactan sobre la sociedad; entre ellos, el cinematógrafo, un invento que detesta y del que se convierte en furibundo enemigo. Pero su figura, andando el tiempo y de manera paradójica, también va a ser motivo de atención por parte del cine. No solo en cuanto a la adaptación de novelas suyas a la gran pantalla; también su propia vida. Es precisamente la última película de Alejandro Amenábar -Mientras dure la guerra (2019)-, la que nos lleva a plantear una reflexión: ¿tiene el cine la capacidad de redimir y perdonar a aquel irredento que tantas veces se ensañó con el medio? El acercamiento que el director realiza a los últimos meses de vida del pensador vasco contiene una serie de constantes iconográficas y simbólicas que fusionan la realidad histórica de los comienzos de la Guerra civil con la percepción personal de situaciones particulares y la ficción fílmica. Su estudio contribuirá a trazar vías para responder a esa pregunta.

\section{Cómo citar este texto:}

Javier González Torres (2021): La mirada de Alejandro Amenábar sobre un enemigo acérrimo: ¿la reconciliación del cine con Miguel de Unamuno?, en Miguel Hernández Communication Journal, Vol. 12 (2), pp. 289 a 308. Universidad Miguel Hernández, UMH (Elche-Alicante). DOI: 10.21134/mhjournal.v12i.1337 


\title{
Alejandro Amenábar's view on a staunch enemy: The reconciliation of cinema with Miguel de Unamuno?
}

\author{
Javier González Torres | javier.gonzalez@fundacionvictoria.edu.es \\ Fundación Victoria, Universidad de Málaga
}

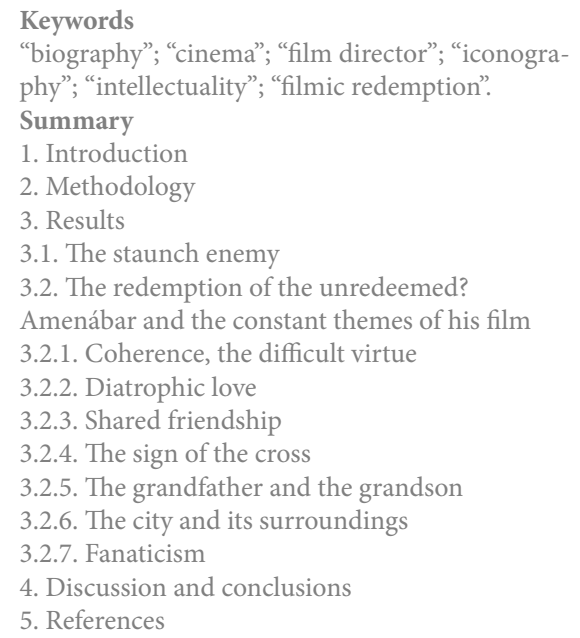

\begin{abstract}
Miguel de Unamuno is a "agitator of spirits". This is the self-definition of one of the most significant intellectuals in contemporary Spanish history. His free, passionate and politically incorrect opinion reveals the subjectivity of someone who observes the multiple factors that have an impact on society; among them, the cinematograph, an invention that he detested and of wich he becomes a furious enemy. But his figure, as time went on and a paradoxical way, would also be the subject of attention in the cimena. Not only in terms of the adaptation of his novels to the big screen; but also, his own life. It is precisely the latest film by Alejandro Amenábar -Mientras dure la guerra (2019)-, wich leads us to reflect: Does cinema have the ability to redeem and forgive that unredeemed
\end{abstract} man who so, often, raged against medium? The director's approach to the last months of the Basque thinker's life contains a series of iconography and symbolic constants that fuse the historical reality of the beginning of the Civil War with the personal perception of particular situations and filmic fiction. A study will help to trace ways to devise this question.

Javier González Torres (2021): La mirada de Alejandro Amenábar sobre un enemigo acérrimo: ¿la reconciliación del cine con Miguel de Unamuno?, en Miguel Hernández Communication Journal, Vol. 12 (2), pp. 289 a 308. Universidad Miguel Hernández, UMH (Elche-Alicante). DOI: 10.21134/mhjournal.v12i.1337 


\section{Introducción}

Miguel de Unamuno y Jugo -Bilbao, 1864/Salamanca, 1936- es un personaje consustancial a la historia contemporánea española. Los múltiples perfiles que encarna quedan plasmados tanto en su extensa producción intelectual como en la multiplicidad de gestos, actuaciones y proyectos que protagoniza. Su personalidad compleja, causante de notables elogios y encendidas críticas, se asienta en el ejercicio de una libertad e integridad personales que le lleva a diferir de corrientes heterogéneas (Marías, 1997: 53). Sus opiniones descarnadas, fundamentadas en su experiencia y políticamente incorrectas, lo convierten en un individuo que utiliza su talento en pro de despertar la conciencia ciudadana y proponer vías alternativas sobre cuestiones de interés (Ouimette, 1976: 315-322).

Este posicionamiento, atento a las circunstancias que le rodean e influido quizá en su formación por Hegel, le lleva a construir un discurso estructurado mediante opuestos: sus posiciones extremas, contradictorias, denotan un interés por tensionar la opinión pública a partir de un planteamiento que dialoga entre posturas de imposible reconciliación (Ribbans, 1989: 160). La historiografía coincide en advertir esa dualidad como característica inconfundible del 'estilo unamuniano', reflejo de un intelectualismo efervescente que provoca la sensación de estar ante un autor que rechaza defender un statu quo inamovible.

Su figura, vista con la perspectiva del tiempo, es la de un original activista intelectual -si se utiliza esa clave conceptual contemporánea- (Roberts, 2007: 13-37). Él mismo se autodenomina como un 'agitador de espíritus', convirtiéndose en creador de un proyecto empírico que sigue suscitando a día de hoy controversias entre quienes reconocen su actuación precursora y los que, a la inversa, lo consideran un excéntrico inclasificable. Esa falta de unanimidad valorativa quizá se deba al antaño estudio parcelado de su producción cuando, en puridad, toda ella es un corpus documental magmático en el que las cuestiones filosóficas se funden con asuntos políticos, sociales, filosóficos, culturales o morales. En la actualidad, tras décadas de reparación de esa brecha metodológica, la apreciación del autor vasco es más equitativa, global y concordante.

El poso dejado en sus reflexiones, analizadas desde poliédricos puntos de vista, concuerda a su vez con la meta que Unamuno se trazó a lo largo de su vida: la de una búsqueda permanente en continua reinvención. En esa línea, sus opiniones son consecuencia de una detenida observación fenomenológica que, por ser cambiante, le lleva a variar impositivamente de enfoque, adaptando su criterio a lo innovador o, por el contrario, reafirmándose en justificaciones expuestas con anterioridad.

Ese ser hijo de su tiempo le permite reconocer el creciente impacto que diversos fenómenos novedosos provocan en el imaginario colectivo; entre esos movimientos se encuentra el cinematógrafo, como suele denominarlo. La popularización de esta industria, la mayor o menor capacidad expresiva de las cintas que se proyectan y las reacciones que advierte en los espectadores, le lleva a preocuparse sobre el mismo en el lapso temporal que transcurre entre los años finales del siglo XIX y las tres primeras décadas de la siguiente centuria. Y 
su percepción, como más adelante se expondrá, augura una crítica negativa sin paliativos.

Pese a ello, la capacidad de viajar en el espacio y en el tiempo que tienen las especulaciones de un personaje tan significativo ejerce una particular fascinación en el mundo del cine. Desde el punto de vista de su producción literaria, la gran pantalla ha proyectado adaptaciones o versiones que convierten complicados textos en imágenes, planos y secuencias. El francés Pierre Chenal es pionero de ello (1943), seguido por Carlos Serrano de Osma (1946), Julián Soler (1954), Miguel Picazo (1964), Rafael Gil (1971), José Jara (1976), Javier Aguirre (1977), Rafael Villaseñor (1982) o José Ángel Rebolledo (1988), entre otros.

Pero también la apasionada vida del escritor seduce a quienes pretenden convertirla en argumento de sus largometrajes. Manuel Menchón estrena en 2015 La isla del viento, una poética recreación cinematográfica de los cuatro meses de exilio que, en 1924, llevó a Unamuno hasta Fuerteventura, castigado por atizar a la dictadura presidida por Miguel Primo de Rivera y congeniada con Alfonso XIII. A pesar de tan sugestivo planteamiento, bien resuelto en cuestiones técnico-formales y amparado en una vasta documentación ${ }^{1}$, el proyecto obtuvo poco respaldo social: $19.479 €$ de recaudación y 3.219 espectadores $^{2}$.

Esos números se acrecientan exponencialmente tras el estreno el 27 de septiembre de 2019 de Mientras dure la guerra, de Alejandro Amenábar. Con guión firmado por él mismo en colaboración con Alejandro Hernández, la película está cerca de alcanzar tan solo mes y medio

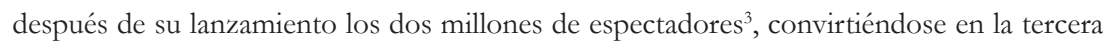
cinta más vista del año en el mercado nacional. Dos nominaciones en los Premios Forqué y cinco Goyas (de 17 candidaturas) conforman su palmarés. Pero quizá, lo más interesante de todo, son las reacciones que la misma provoca tras su visualización: la de un reposicionamiento del espectador ante el personaje y los hechos por este vividos, motivado también por la amplia repercusión mediática obtenida.

La relevancia internacional de su director, el notable éxito de público alcanzado -continuado gracias a la exhibición en la plataforma audiovisual de Movistar- y las críticas que sobre la película se han vertido en distintos ámbitos, nos lleva a plantear una reflexión: ¿tiene el cine la capacidad de perdonar a quien tantas veces se ensañó con el medio? ¿Conoce el director el pensamiento tan crítico que Unamuno defendía y, pese a ello, ofrece una visión renovada del mismo? Estas preguntas quizás son más retóricas que respondibles con contundencia. No obstante, a lo largo de las siguientes líneas se tratará de analizar una posible redención del medio, aprovechando los intersticios de opinión que existen en los planteamientos de uno de sus críticos más feroces.

${ }^{1}$ El desarrollo de estos será motivo de estudio transversal en otro artículo en ciernes.

${ }^{2}$ Datos recogidos por el Instituto de la Cinematografía y de las Artes Audiovisuales (ICAA).

${ }^{3}$ Información ofrecida por los medios de comunicación en esa fecha, recogiendo a su vez datos facilitados por el ICAA. 


\section{Metodología}

Para realizar una aproximación a los aspectos iconográficos empleados en la construcción del personaje principal, será de aplicación en este estudio una metodología que contraste diversas fuentes documentales, especialmente las firmadas por el propio Unamuno, con el sustrato teórico empleado en el guion. Este proceder analítico es crucial para comprender los mecanismos utilizados en la concreción del protagonista así como las diversas significaciones que derivan de su lectura. De esta manera podrá advertirse cómo Amenábar hace uso de una serie de constantes temáticas, plagadas de densidad simbólica, cuya interacción pondrán en jaque la realidad histórica, la percepción subjetiva y la ficción, contribuyendo a la formación de una determinada y sugestiva personalidad.

\section{Resultados}

\subsection{El enemigo acérrimo}

De entre los artículos que Unamuno publicara destacan, sobre todo, aquellas apreciaciones que realiza sobre el cine. Una lectura comparativa y transversal de estas indica que el medio le atrae lo justo. No es asiduo de las salas cinematográficas, ni en sus reflexiones quedan anotados visionados de títulos concretos. Sin embargo, la contundencia conferida a ciertas afirmaciones lo convierten en un "espectador" con criterio que formula asertos basados en su propia experiencia. Un alto porcentaje de estos lo sitúan como un "cinematófobo furibundo", siguiendo el neologismo aplicado por Caro Baroja, en boga entre los más conocidos miembros de la Generación del 98 (Utrera, 1982: 118-122).

De entre las críticas vertidas, las más negativas atacan a la esencia misma del cine, a la procedencia etimológica de cada tecnicismo derivado del universo audiovisual o la inexistente relación que, en su opinión, tienen los montajes finales con el mundo literario. Sin embargo, hay un atisbo de benevolencia en otro aspecto consustancial: la capacidad de las imágenes en movimiento para suscitar en el espectador cierta curiosidad imaginativa hacia intereses estéticos.

Hórrido, antiartístico o fatídico son algunos de los epítetos conferidos para denigrar la capacidad expresiva de una película y la artisticidad que esta se le presupone. Valga como ejemplo el siguiente fragmento:

Vi que al cinematógrafo se le llama el séptimo arte. ¿El séptimo? Supongo que los otros seis serán: pintura, escultura, arquitectura, baile, música y poesía. Pero lo mismo podría ser el noveno si incluimos también la sastrería y la tauromaquia o toreo. Y debo confesar, antes de seguir adelante, que el cine me molesta bastante. Primero a los ojos y luego al espíritu. No puedo resistir el que me quieran dar un drama pantomímico donde hacen falta palabras y que luego proyecten en la pantalla un letrero en que se me cuente lo que han dicho o han de decir los que aparecen gesticulando y hasta moviendo los labios, que es como si tocaran 
la música del tango que se ha visto o se verá bailar. Y he aquí por qué un literato, un verdadero literato, un poeta, cuyo instrumento es la palabra, un artista del verbo, no puede escribir para el cine. ¡Escribir para el cine! Será dibujar a lo sumo $[\ldots]$ (Unamuno, 1923).

En otras ocasiones, las alusiones cinematográficas aparecen unidas a otros temas. Así, la gestualidad propia del mundo fílmico es asociada al comportamiento de determinados políticos, acusados de representar funciones más fantasmales que reales. Una actitud definida como "cine parlamentario": gestos vacíos o aparatajes escénicos en los que se envuelven determinadas personalidades públicas, desvían la atención de lo verdaderamente importante y apartándose del contraste de ideas.

No está de acuerdo tampoco con el exhibicionismo de las actrices que exponen sus cuerpos desnudos o lucen con desdén las virtudes del maquillaje, calificándolas de "mozas de la pantalla que parecen fabricadas - no engendradas ni paridas- en serie" (1934). Como, en igual sentido, reniega de ciertos comportamientos que se advierten en algunas películas, o incluso deportes, que se traducen en acciones violentas protagonizadas por jóvenes maniqueos que se dejan llevar por aquello que han visto (1932).

Tanto el segmento actoral como el juvenil son para el escritor vasco reflejo de una sociedad dual donde lo natural choca con el progreso de la civilización, posicionándose a favor de la agudeza de entendimiento, del mantenimiento de la cultura tradicional y de los misterios de la ciencia. Esta trilogía de apreciaciones resulta esencial para hacer frente al envoltorio superfluo que promueven las tecnologías comunicacionales (1966, p. 886). Es como si las innovaciones mecánicas impidieran a los seres humanos disfrutar de las bondades eternas de las relaciones sociales o el paisaje, convirtiendo la sensatez de otras épocas en locura o idiotez actuales.

Advierte así del desarrollo de un proceso general en el que lo individual queda relegado a un segundo plano, siendo sustituida la persona per se por la muchedumbre; una masa que actúa cual rebaño inconsciente movido por intereses espurios es un peligro para la inteligencia. A ese "apesebramiento" colectivo contribuyen, entre otros, el cine y la fotografía, el teatro contemporáneo e, incluso, la radio; medios falsos que incluso desaparecerían con el tiempo víctimas de "su propia exageración” (1959: 1387).

Ese público, que también se sienta en escaños del Parlamento o en el tendido de una plaza de toros, queda para el autor preso "del más lamentable sensacionalismo [...] que cultivan, para sus fines industriales, los explotadores técnicos de él, los que viven del agiotaje de la actualidad" (1922). Y es en esos espacios masivos como la sala de proyección, el hemiciclo o el ruedo, donde la Historia no encuentra registros en los que perpetuarse, pues lo que allí acontece son simples 'sucesos' olvidables, contrarios a los 'hechos' perdurables en el tiempo que, ontológicamente, sí contienen un sustrato y sentido históricos.

Ahondando en estas consideraciones e hilando juicios valorativos variados, en otro artículo se expresa de la siguiente manera: 
¡El cine! ¡Espectáculo característico para una sociedad dominada por el sentimiento de la transición! ¡Y espectáculo para sordos! Para sordomudos, más bien. De donde se acaba creyendo que la historia viva, la presente, la siempre presente, es cinematografía muda y que nada dice. Y así nada queda de ella. Porque en la Historia lo que realmente queda es lo dicho, la palabra (1920).

Estos asertos no son originales. Emilia Pardo Bazán o Antonio Machado ${ }^{4}$ comparten la misma idea: el cine no tiene capacidad epistemológica para ser una obra de arte. Ahondando en ello, establece una asociación explícita que distingue, primero, entre la imagen y la reacción instintiva y, segundo, entre palabra y pensamiento. De ahí su empeño en proponer que el cinematógrafo no proyecte un ideal racional pues es incapaz de convertir la imagen visual en una fuente de conocimiento directo. Tan solo reproduce una intención mecánica e involuntaria, diametralmente opuesta a la praxis artística. De ahí que las películas -las mudas en especial- no puedan ser nunca una expresión estética ni representacional; les faltan palabras, son "un teatro sin literatura" (1916).

Esta línea de pensamiento entronca con aquellos otros teóricos que afirman que para que toda expresión artística exista, debe contar una historia, presentar unos personajes creíbles y expresar unos sentimientos determinados 5 . Pero el cine de por sí no lo puede conseguir porque sobre el mismo siempre se cierne otra duda: ¿puede una máquina -el cinematógrafo- ser un canal expresivo de aquello que solo está reservado a lo humano? (Cerezo, 2017: 125-126). Unas reflexiones que culminan cuando Walter Benjamin (1935) afirme tajantemente que el cine es el principal agente de la destrucción del 'aura de la obra de arte' y que, pese a su carácter social, terminará aniquilando el valor tradicional de la cultura.

Insiste en esa despersonalización del comportamiento el autor vasco (1936): el cine $e^{6}$ está "arrebatando el toque del mundo, el contacto íntimo con él. Nos están imbuyendo, sin que nos demos de ello clara cuenta, el sentido -o mejor, el contrasentido- de la irrealidad". Y todo por la ausencia de expresión que percibe, una característica esencial para la formación social de la persona pues "conciencia, espiritualiza, humaniza lo animal que hay en el ser humano". Esa notoria carencia termina convirtiendo al espectador en un fantasma desilusionado, un alma en pena.

Y el convencimiento propio impide a Unamuno proyectar su empatía hacia esos medios que, como el audiovisual, distorsionan el conocimiento: "Si eso otro es arte -que no lo es-, me chiflo del arte y me quedo con la vida" (1909). La siguiente aseveración resulta absolutamente concluyente (1966: 601): "El público no quiere oír, no quiere tener que pensar. Le

\footnotetext{
${ }^{4}$ No hay unanimidad entre los miembros de la Generación del 98. Véase a Valle-Inclán o Azorín, por citar a dos de sus más destacados defensores, capaces incluso de incorporar técnicas cinematográficas a sus producciones literarias.

${ }^{5}$ En una posición diametralmente opuesta se encuentra Ortega y Gasset, por ejemplo.

${ }^{6}$ Se debe incluir ya al sonoro, como expresa específicamente el autor en su artículo. En España, la adaptación progresiva de los proyectores tiene lugar a partir de 1929.
} 
basta el argumento. No quiere saber lo que los personajes piensan de sus propios actos y cómo tratan de justificarlos. Le basta el gesto, lo más inconsciente".

A pesar de lo expuesto, entiende que el éxito del medio si tendrá un efecto reformador sobre el arte dramático contemporáneo. Él mismo comienza a escribir piezas teatrales que buscan depurar el drama -en un sentido aristotélico, ligado a la 'desnudez clásica'-, convirtiéndose en la base para que autores posteriores, como Federico García Lorca en sus Bodas de sangre, concreticen proyectos sobresalientes (Dougherty, 2001: 6-25).

Y ahondando en el devenir de la sociedad, movida por la agitada época en la que vive, el escritor (1919) explicita su específico concepto de Historia asociándolo al término de 'cinematógrafo caleidoscópico’: un prisma de espejos que cada persona lleva en su ser y que le aporta certezas gracias a la sensación de continuidad que ofrece, similar a cuando el aparato mecánico proyecta la cinta de una película sobre una pantalla. Una metáfora que, de por sí, es también aplicable a la vida de la conciencia humana, convertida en pauta filosófica esencial para el pensamiento unamuniano y que actúa ajena a todo espectáculo.

Quizá aquí se encuentre, en la tensión pretendida que el autor realiza entre posiciones antagónicas, las únicas salvedades positivas que deduce en sus reflexiones sobre el cine. Y el descargo procede de la cinematografía documental, aquella que permite abrir vías para acercarse hasta la esencia misma de un determinado hecho. En este sentido, el autor reconoce que "algo está ayudando el cine [...] al desentumecimiento de la córnea imaginación de nuestro público de "aficionados". Las truculencias vistas le están despertando el interés, digamos estético, de otros espectáculos" (1966: 977). Conclusiones a las que llega tras conocer, en plena I Guerra Mundial, la actividad de un joven director, documentalista, herido durante la filmación de un enfrentamiento bélico (Fernández Urbina, 1989: 83).

No se trataría de una capacidad intrínseca al medio sino, más bien, de la extrapolación intelectual de alguno de sus elementos configuradores. Un ejercicio reflexivo, ni masivo ni popular, solo al alcance de quien fuese capaz de desbrozar la 'mala hierba' que crece junto a la "buena semilla". Esta acotación serviría para plantear la existencia de una vía estética en la que la interacción de elementos audiovisuales, alejados de lo ficcional y más próximos a la verdad empírica, condujese a la aplicación de consecuencias factibles y positivas. Eso sí, ¿aptas para el individuo o para todo tipo de públicos? Difícil conjunción de aquel que anduvo obsesivamente preocupado por la identidad personal, repensando una y otra vez la realidad o irrealidad.

\section{2. ¿La redención del irredento? Amenábar y las constantes temáticas de su película}

Acercarse a Miguel de Unamuno es un reto embarazoso, lleno de sorpresas y casi inabarcable. Son quizá algunos de esos elementos consuetudinarios a su forma de ser los que han llamado la atención de Alejandro Amenábar. No en vano, el director, al explicar las motivaciones que le han llevado a congeniar la trayectoria vital del escritor con el hilo argumental 
de su película, destaca que es justamente la peripecia un elemento expresivo clave, "oro puro" para la dramatización (Yuste, 2019). No en vano y de entre las controversias que el escritor experimenta, las vividas en los últimos meses de su vida pueden ser las que un mayor impacto le han causado.

En ese ejercicio aproximativo, el director apuesta por la humanización de los sentimientos construyendo una ficción que tiene una base histórica indudable, aunque, en algunos momentos, tienda tanto al drama como al thriller, en una libre -y criticada por algunosinterpretación de hechos, gestos y acciones. Así, lo primero es acotar el espacio temporal a narrar, eligiéndose el periodo que transcurre entre julio y diciembre de 1936; comienza con el fracaso del golpe de estado militar que desencadena la Guerra Civil y termina con la reclusión domiciliaria del protagonista tras su intervención en el paraninfo universitario, el 12 de octubre.

De esas vivencias, Amenábar intenta bucear en el Unamuno más íntimo: el exigente padre, el cariñoso abuelo, el compañero divergente, el amigo cascarrabias o el docto intelectual, sin olvidar el replanteamiento constante que el escritor realiza en su fuero interno en función del análisis de los acontecimientos que vive. En la búsqueda de esas tramas personales, el director destaca la interesante sustancia que supone acercarse a alguien que es capaz de oscilar por las distintas tonalidades de grises que separan los polos opuestos. Aquí reside la meta narrativa que pretende alcanzar la película: trazar una cierta verdad sobre el personaje, partiendo de matices insertos en las obras unamunianas.

El interés de la cinematografía por convertirse en complemento de la historiografía es antiguo. El punto clave -no siempre conseguido- es el de mostrar miradas diferentes que actúen cual vehículos de actualización y compresión de hechos pasados a través de un planteamiento emocional. El relato fílmico que deriva de tal premisa, incluso tomándose licencias que hacen prevalecer unas cuestiones por encima de otras, debe estar próximo a la caracterización misma del personaje principal. Y, en este caso, y al igual que ocurre en la novela Niebla, por poner un ejemplo ad hoc, cabe incluso preguntarse si Amenábar tiene la intención de ofrecer matices diferentes -haciendo uso de una particular técnica de perspectiva múltiple- para que, a la misma vez, impacten sobre la verdad intrahistórica para, así, descomponerla en distintas significaciones.

En ese préstamo literario, el director es deudor de una asentada colaboración entre disciplinas, indagando de manera analítica en el perfil más introspectivo de Unamuno. Y es que existe una corriente de opinión que asegura que la mayor parte de los personajes que aparecen en las reflexiones del escritor -no solo en sus novelas, sino también en otros textos dialogados- tienen un trasfondo autobiográfico (Gullón 1976:205). Incluso se llega a afirmar que la complejidad psicológica que ofrecen pueden ser un impedimento para llevar cualquier adaptación fílmica (Gómez Mesa, 1978:261).

La continua ruptura de la linealidad narrativa sitúa al director en un doble punto de referencialidad: de un lado, siguiendo criterios puramente cinematográficos, a las prácticas que David W. Griffith instaurara, tanto por el seguimiento de las técnicas expresivas como por 
resaltar valores formales y estéticos; y, de otro, a la audacia metaficcional que Unamuno confiere a sus novelas, en las que crea un efecto de cercanía/lejanía con la realidad y a la interiorización psicológica de sus personajes (Álvarez de Castro, 2014: 9-13). En esa apuesta arriesgada quizá se contenga un último objetivo que escapa a la percepción del director, pero que plantea el interrogante inicial de este trabajo: todo esto, ¿ayuda a conseguir una redención fílmica de Unamuno con el cine?

La línea documental que el escritor salvaba en su enérgica crítica al medio es la que, quizá sin saberlo a ciencia cierta, plantea Amenábar. En el ejercicio reflexivo realizado por el director en torno a figura central de su largometraje, se plantean una serie de constantes temáticas cuya lectura de conjunto conduce a la esencia del perfil propio de Unamuno, siendo por ello más propias de la verdad empírica que de hechos ficticios. Abordar así a quien tanto empeño puso en denostar al cine supone, en cierta medida, colarse por los escasos intersticios que el escritor vasco concedió en sus escritos para centrarse en plasmar una síntesis biográfica de su particular universo. En ese ejercicio introspectivo, siete vías temáticas resultan ser trascendentales en cuanto concienzuda síntesis entre los asertos del escritor y su traducción visual, cumpliendo así con los dos planos representativos -el descriptivo y el narrativo- inherentes a todo proyecto fílmico (González Requena, 2000).

\subsubsection{La coherencia, esa difícil virtud}

Unamuno asegura en el prólogo de La agonía del cristianismo (1931) que aún le "queda darle más vueltas y darme yo más vueltas", siendo consciente de sus inquietantes contradicciones e interminables luchas internas. Una tolvanera de controversias que cobra mayor fuerza a raíz de la convulsa situación político-social que vive España en esa década.

Ese 'estado natural' es inmutable y puede rastrearse perfectamente, por ejemplo, en sus adscripciones políticas: en su juventud, simpatiza con el PNV, exaltando el carácter propio de su tierra. Posteriormente, milita en el PSOE y ejerce una dura oposición tanto a Alfonso XIII como a la dictadura de Primo de Rivera. Una vez proclamada la II República en 1931, en la que se llega a manejar su candidatura para presidirla, es elegido diputado por Salamanca. Sin embargo, sus continuas divergencias personales con Manuel Azaña y otras decepciones, le llevan a empatizar con los militares que promueven una sublevación en la búsqueda de un orden que ponga fin al caos que, a su juicio, envuelve a la nación.

El continuo razonamiento interior que vivencia en Mientras dure la guerra es propio del quehacer unamuniano y supone una marca indeleble de su estilo literario. El interés por profundizar de manera introspectiva en el personaje conecta a Amenábar con Unamuno y, a su vez, al universo de la novela modernista española: a lo largo de todo el metraje se hace un uso de una narración subjetivada, antipositivista de la realidad -en clave de autoficción-, con tramas que se ralentizan y fragmentan, destacando el desarrollo psicológico del escritor, sumido en multitud de ocasiones en estadios de seminconsciencia. Podría constituir este punto inicial un homenaje al 'monólogo mental" con que el intelectual se identifica en su primera novela, Paz en la guerra, de 1897, y que convierte en recurso fenomenológico para 
posteriores ensayos (Garrido Ardila 2012-2013:445-446 y 561-563).

$\mathrm{Al}$ dudar de continuo se refiere Amenábar en diferentes entrevistas, argumentando que, en Unamuno, "su aparente cambio es porque sus principios son inamovibles" (Academia de Cine, 2019). Una ambigüedad digresiva que es seña identitaria, reflejada tanto en su vasta producción intelectual como en sus acciones y que, en la película, se muestra descarnada. Y no solamente por los giros en los diálogos sino, también, por el uso continuado de planos cortos, a veces puntuales que, centrados en su figura, suscitan una correlación entre realidad y percepción.

Esta primera constante persigue también establecer un método de acercamiento al personaje a partir de otra cuestión básica: aquella en la que el guion expone sucesos que fluyen y cambian, pasando de una superficialidad genérica a la construcción de una esencia particular, suficientemente argumentada, tendente a la configuración de la realidad interior.

La apuesta es a su vez consecuencia de dos factores: por un lado, las particulares rutinas del director; y, por otro, la propia existencia del escritor, que podría conceptualizarse de inconclusa. En efecto, en la filmografía de Amenábar pueden advertirse fórmulas narrativas que la que el protagonista expone su vida en forma de relato autobiográfico, buscando la justificación oportuna para cada una de sus acciones. Así ocurre en la focalización de César, el personaje principal de Abre los ojos (1997); el accidente que cambia su vida y la búsqueda de un método que palie su deseo de recuperar su desfigurado rostro son mostrados desde la óptica particular de este, conectando con los espectadores a través de la distorsión entre realidad y pesadilla (Sulbarán y Cruzco, 2018:54-55).

En cuanto a Unamuno, la visión simplista de la incoherencia advertida en sus reflexiones es la que se convierte, en puridad, en un acto voluntario de contradicción. De esa confrontación nace la coherencia de quien se encuentra en conflicto permanente consigo mismo y frente a voluntades antitéticas; una actitud que es consecuente con su desesperada visión del ser humano (Meyer, 1955), en una posición más cercana a la mística que a las corrientes de pensamiento contemporáneas. Tal cuestión intenta ser captada por Amenábar a partir de acciones en las que se patentizan sus dudas en función de la percepción de una serie de hechos que desencadenan una reacción contraria a aquello que, en un principio, parece apoyar.

El proceso, premeditado o no, alude a su vez y de manera curiosa a las opiniones que sobre el cine tiene Unamuno y constituyen de por sí un ejercicio de coherencia con su forma de entender la vida: la decidida apuesta por la in-versión y fundamentada a partir de un proceso reflexivo, es una oposición firme a la di-versión colectiva que, de forma irracional, renuncia a la individualidad para convertirse en una masa informe que ciegamente sigue órdenes y desarrolla instintos de odio hacia todo aquello que considera contrario.

${ }^{7}$ Conceptualización realizada por Unamuno en el prólogo de la segunda edición de Amor y pedagogía. 


\subsubsection{El amor diatrófico}

En la película hay una presencia continua en la mente del protagonista: la de su esposa, Concepción Lizárraga Ecenarro, fallecida en mayo de 1934. Su óbito reciente 'obliga' a Unamuno a dejarse llevar, en una incursión extemporánea, hacia momentos de unión placentera a través del recuerdo. El contacto entre quienes se profesan un amor incondicional y maduro, interrumpido tajantemente por la muerte, conduce al marido a anhelar los momentos perdidos a través de un ejercicio interior que acaba reforzando el vínculo del amor con que se identifica la pareja. Se trata, a su vez, de desarrollar una experiencia que el escritor ya había plasmado en múltiples ocasiones en sus textos, buscando a través de la evocación afectiva la necesaria paz ante acontecimientos adversos del devenir cotidiano (Sandoval Ullán, 2004) así como, también, el debido freno a su impetuoso carácter.

De esta manera y a lo largo del metraje, diversos flash-backs entendidos cual alusiones subconscientes sitúan a los amantes recostados, el uno sobre la otra, en una frondosa pradera y a la sombra de un roble. El aspecto de ambos -salvo en una ocasión- es el de dos jóvenes ensimismados, aislados de cuanto acontece alrededor. Él parece buscar en el regazo de ella un plácido sosiego, convirtiéndose así la figura de la esposa en un referente sumativo de dos realidades complementarias: la de compañera y la de madre. Una actitud vital que satisface el ansia del hombre-hijo, deseoso de recuperar instantes que solamente siguen vivos en su memoria.

Para ello, la obra unamuniana sigue sirviendo de fuente de inspiración inequívoca. Además de los símbolos freudianos que son evidentes en el comentado binomio (Blanco Aguinaga, 1959), el recurso del sueño supone la concretización de un trasunto imbuido en la estructura planteada por Unamuno en su primera novela, Paz en la guerra, publicada en 1897. Así, la concretización de una realidad onírica constituye el modo mediante el cual provocar la invocación y el premeditado encuentro con un amor espiritual, superior no solo al carnal sino a la propia existencia; un sentimiento psicosomático, diatrófico.

Como igualmente aparece reflejado en Niebla, la descripción de la existencia humana del protagonista en la película oscila entre la conciencia y el mundo de los sueños, completando así una realidad múltiple en la que existe una certeza inmutable: el amor es lo único eterno de la vida y es capaz de devolver al presente experiencias pasadas. Se trataría pues de precisar una trama afectiva que, en determinados momentos, se hace presente para otorgar consistencia a la personalidad del protagonista.

De igual manera, esas remembranzas se refuerzan, a su vez, con el uso de un objeto doméstico: la fotografía del matrimonio, enmarcada y dispuesta en los anaqueles del despacho. Un recurso recurrente que, al igual que la anteriormente citada novela, contribuye a identificar los anhelos del marido nostálgico con el carácter sobreprotector que adquiere la presencia/ ausencia de la esposa. Siguiendo a Augusto, el protagonista de Niebla, el Unamuno de Amenábar ejemplifica en estas secuencias aquella sentencia que afirma que "el amor es un éxtasis; nos saca de nosotros mismos" (1914:52). De ahí que 'la costumbre' a la que se aferraba 
el escritor desde que los amantes se conocieron sea la misma tónica a la que alude, en esa misma línea, cada vez que en una conversación con su nieto o con sus amistades recuerde a Concha (Migueláñez González, 2020: 433-439).

\subsubsection{La amistad compartida}

Uno de los ejes dramáticos que subyacen en la trama de la película pivota sobre la relación establecida entre el protagonista y dos personas: el pastor protestante Atilano Coco y un profesor de la Universidad de Granada, otrora antiguo alumno, Salvador Vila. La presencia de ambos tensiona el espíritu del escritor, obligándole a emprender acciones concretas o a guardar un miedoso silencio.

De la relación existente entre los tres, asentada en la documentación y los estudios llevados a cabo al respecto, Amenábar realiza una versión libre para plasmar a los actores ${ }^{8}$. Aprovecha las detenciones del religioso de mediana edad, primero, y del joven docente, después, para sentar las bases de la reacción de Unamuno frente al injusto atropello cometido. A lo largo de la película se advierte que la explosión final que lleva al escritor a intervenir en el episodio del Paraninfo tiene que ver, sobre todo, con el trato denigrante que los militares han proferido a sus amistades, apresándolos con la excusa de su simpatía por la masonería y las fuerzas de izquierdas, respectivamente.

El trío de caracteres alcanza su cénit dramático en la contraposición de las ideas que cada uno de ellos defiende, acrecentada incluso por una actitud diferente en función de las distintas edades con las que han sido caracterizados: la ancianidad terca e impaciente, la madurez incrédula y la juventud impulsiva. Unamuno no escucha a quienes le advierten de los peligros que se acechan, restando crédito a la opinión de sus dos amigos y enrocándose en su propia visión. El comentado giro de guion que propicia el asesinato del religioso y del docente convierten en dudas lo que antes habían sido certezas, poniendo el acento en el valor de la amistad entre distintos.

\subsubsection{El signo de la cruz}

La tradición judeocristiana marca la personalidad de Unamuno posicionándose a favor de los valores que encarna la civilización cristiana occidental. De ahí que la presencia de los símbolos y signos más tradicionales encuentren en el metraje su debida referencialidad. Al abordar esta constante, Amenábar enmarca el problema religioso del protagonista dentro de los parámetros de su misma visión ontológica; es decir, que su tratamiento formal se patentice en términos de angustia metafísica y sentido trágico. Si habitualmente es el pensador el que plantea aquellos eslabones que inquietan a la conciencia social, cómo no va a ser él mismo el que, en su propio ser, se cuestione aspectos entendidos como inmarcesibles.

${ }^{8}$ A diferencia de lo contenido en la película, Atilano Coco es fusilado con treinta y cuatro años el 9 de diciembre, a las afueras de Salamanca; Salvador Vila, que acababa de cumplir los cuarenta, sería ajusticiado el 22 de octubre en Víznar, Granada. 
Es en esa línea donde Dios, en su eternidad, es equiparado al sufrimiento, a la más alta expresión de la agonía filosófica. La secuencia clave en la que se patentiza dicha visión sitúa al anciano en casa, sufriendo los efectos de un fuerte constipado; en medio de un delirio, se levanta de la cama pidiendo explicaciones a la talla de un crucificado. Los recuerdos se mezclan así con la honestidad de quien, haciéndose presente en la vida pública, no comprende cómo algunas mentes puedan anteponer intereses espurios y prácticamente indefendibles a otras pretensiones más lógicas.

Al tratar de este modo la particular relación entre Unamuno y la fe, Amenábar apuesta por aludir al demonio familiar con voz de conciencia para torturar e increpar al protagonista. Este, en su obra literaria, ya había utilizado ese mismo recurso narrativo, anticipándose a los flujos de conciencia que recogieran Joyce, Proust o Woolf (Garrido Ardila, 2012). No en vano, en Amory Pedagogía, de 1902, se advierte cómo su personaje central, Avito Carrascal, percibe unas voces internas que le invitan a reconocer el error de interpretación de la realidad en la que vive. El sueño crónico, ese soñar despierto sin evadirse por completo del mundo real, enlazado con las tesis freudianas, se hace presente de esta manera en la película interpelando a la conciencia unamuniana para, a su vez, sumirla en un estado de mayor confusión si cabe.

\subsubsection{El abuelo y el nieto}

De entre los personajes que pueblan la casa de los Unamuno y, de una manera más prosaica que fidedigna, el guion confiere suma importancia a la presencia de uno de los nietos del pensador: un niño de aproximadamente siete años. Entre el abuelo y el chico se establece un vínculo afectivo que hace sobresalir el lado más entrañable, sencillo y cercano del primero al encontrar, en la inocencia del segundo, la comprensión que no haya en otras personas de su entorno.

La nostalgia de un tiempo perdido y la orfandad provocada por la ausencia de los seres queridos son las dos pautas escogidas para la caracterización de esta relación; la situación que viven ambos parece asimilarse tanto por el complejo contexto histórico que comparten como por haber perdido, respectivamente, a su esposa y a su padre, activo en el frente de guerra. Es el niño el que, en ocasiones, hace volver a la realidad al anciano, abstraído en ese duermevela que lo aísla de la realidad.

Para reforzar tal idea, Amenábar utiliza el recurso de la papiroflexia, convirtiendo esta habilidad manual en una vía de acercamiento entre dos personas de edades distintas. Pequeñas figuras de animales sirven para que el abuelo logre la cómplice sonrisa del nieto que, a su vez, también actúa de conciencia particular cuando se asusta al oír las noticias de la radio o al cortarse la luz de la casa. Esas escenas melodramáticas actúan de contrapunto a las tramas principales, captando la atención del espectador a través de expresiones más sensibles. 


\subsubsection{La urbe y su entorno}

Hasta quince localizaciones distintas de Salamanca se ofrecen en la película. La plaza Mayor y a la Universidad -el patio de Escuelas Mayores, las escaleras de este y las galerías del segundo piso-; la fachada de la Casa-Museo del escritor ubicada en calle Libreros, el puente romano, las calles de Bordadores, Compañía, Cervantes, de la Veracruz - donde se sitúan las casas de dos amistades más cercanas-, Tavira, Serranos - con la trasera la Universidad pontificia y la facultad de Geografía e Historia-; y, entre los edificios religiosos, descuellan la iglesia de san Martín o la Catedral vieja.

Intensa es la relación que Unamuno establece con la urbe helmántica tras cuarenta y cinco años de estancia en la misma, pese a que sus primeras apreciaciones, recién llegado de Bilbao, no fueran buenas. El tono dorado de la arenisca pétrea de Villamayor con que están construidos los edificios más significativos de su Centro histórico, adquieren importancia en la captación escenográfica de los espacios en los que se desarrollan las tramas. Los rutinarios paseos enlazan aquellos lugares básicos de su diario quehacer constituyen, de por sí, la recreación de un idilio más asentado en cuestiones académico-filosóficas que pasionales.

Al respecto, Amenábar trata de exprimir la plasticidad fotográfica que imprime la poderosa presencia de Unamuno por las calles de la ciudad del Tormes - contundente en su físico, siempre enlutado, tocado con la clásica chapela vasca y haciendo uso de un bastón de apoyo-, intentando recrear aquellos versos que el propio filósofo escribiera y en los que solicitaba a aquellas piedras inertes que guardaran su recuerdo cuando falleciera. Se trata quizá de uno de los aspectos estéticos más sobresalientes de la película que, de por sí, dotan de mayor credibilidad su engranaje narrativo.

\subsubsection{El fanatismo}

La mitificada escena del Paraninfo universitario es el punto álgido del dicotómico enfrentamiento que surge entre la acción represiva de los militares rebeldes y la erudición intelectual. Tal contraste se pone de manifiesto en el posicionamiento dialéctico ejemplificado por la verborrea beligerante del general Millán Astray y la contundencia mayéutica de Unamuno. Teniendo en cuenta las diversas versiones existentes sobre un acontecimiento de cuyo desarrollo exacto aún se tienen dudas, Amenábar prefiere ahondar en la caracteriología particular de ambos personajes con tal de establecer nítidas diferencias entre sus argumentos, posicionamientos y estilos empleados.

El exacerbado clima de rechazo hacia las palabras del escritor llega a tal paroxismo que el director opta por recrear de manera libre la precipitada salida de la sala del aún rector, guiado por Carmen Polo. El contraste de esta situación con fuentes documentales y fotográficas es aún más evidente cuando ambos se adentran en un coche y mantienen una conversación en la que la esposa de Franco le reprocha su actitud, pues le consta que esas situaciones tan extremas no son las que desea su marido. 
Amenábar, respecto a la contraposición de caracteres, opta por una cuestión tradicional en la historia del cine: la delimitación prototípica entre el bien y el mal' ${ }^{9}$. Es evidente que, en este sentido, sigue el acostumbrado proceso fílmico tendente a construir valores de aceptación y rechazo a aquello que sobresalta el ánimo del espectador, reposicionándolo ante hechos concretos. En cualquier caso y respecto al clima de crispación que debió vivirse en el espacio universitario -que no es más que un episodio más de la cruenta guerra iniciada-, es complejo mantener la equidistancia y no empatizar con quien denuncia que el fanatismo ciego elimine todo atisbo de sosiego al debate dialéctico.

\section{Discusión y conclusiones}

La pregunta con la que se inicia este estudio es compleja de responder. Sin embargo, en cuanto a la construcción del protagonista y al hilo de las constantes expuestas, pueden extraerse algunas consideraciones. Por ejemplo, la adaptación digresiva de la historia realizada por el director de Mientras dure la guerra con la intención de adaptar el relato a su personalista visión sobre Unamuno, contribuye a su conversión en héroe de carne y hueso al que le está permitido, pese a su reconocimiento intelectual, dudar de continuo. Al respecto, Amenábar se siente fascinado por la vigorosa personalidad del escritor, excusándose en ello con tal de modificar o minimizar aspectos históricos contrastados ${ }^{10}$. Para el director, su trascedente aportación a la historia de las mentalidades está por encima de las opiniones críticas particulares vertidas sobre la cinematografía, siendo esta, precisamente la vía utilizada para enaltecer su figura.

Teniendo en cuenta pues que no hay equidistancia imparcial en este premeditado homenaje, la película ensalza al protagonista haciendo uso de ese estudiado crisol de perspectivas diferentes que intenta captar su esencia diversa y controvertida a través de un estudiado proceso documental. A su consecución contribuye igualmente la caracterización y las dotes interpretativas del actor que lo encarna, Karra Elejalde.

La toma de perspectiva temporal y el revisionismo historiográfico que desliga a Unamuno de la propaganda falangista con la que se envolvería los meses previos y posteriores a su muerte (Rabaté, 2018; Delgado Cruz 2019) ${ }^{11}$, propician la construcción de un personaje fílmico donde lo emocional y lo dramático cobran especial significación. Habrá pues que seguir indagando, parafraseando a Unamuno, en los hunos y en los hotros para entender si es esta ocasión el cine puede redimir a aquel que con tanta vehemencia lo criticó, sirviendo en la actualidad de plataforma de relanzamiento público de su figura y su obra.

${ }^{9}$ Un giro similar planteaba en Ágora (2009), mostrando el choque entre ciencia, religión e ignorancia a través de la figura histórica de Hipatia de Alejandría.

${ }^{10}$ Son diversas las críticas que subrayan los fallos históricos más sobresalientes de la misma, relacionadas sobre todo con las acciones protagonizadas por los mandatarios militares. 
La visión de Amenábar del personaje gana en capacidad expresiva, desligando su figura y su opinión de aquellos epítetos negativos proferidos por el propio escritor en sus textos hacia la cinematografía. Este Unamuno no se integra en un drama pantomímico, aunque ciertas figuras que lo rodean si estén más próximas a lo fantasmal que a lo real. Quizás la caleidoscópica visión que plantea el director -siguiendo el espíritu unamuniano- ayude a desentumecer las córneas de quienes se alejan de lo empírico y buscan reescribir a su manera, en un alarde de exageración sensacionalista, episodios concretos de la historia. De esta forma, la palabra, el método científico que indaga en múltiples fuentes con tal de establecer un relato fiel a situaciones vividas, son siempre la base para el conocimiento, la memoria y la identidad comunitarias. $Y$ en ese sentido, siguiendo su particular coherencia personal, si se puede encontrar, una vez más, al escritor vasco en todo su ser contradictorio. El cine lo ha devuelto a la esfera de lo público; ;quién se lo iba a decir!

\section{Bibliografía}

Academia de Cine (2019). Encuentro con Alejandro Amenábar [Archivo de video]. Recuperado de https://www.youtube.com/watch?v= ${ }_{\text {vEkwlVMhiKo }}$

Álvarez de Castro, L. (2014). Nivola y metaficción en la narrativa española de vanguardia. Ínsula 807, pp. 9-13.

Blanco Aguinaga, C. (1959). El Unamuno contemplantivo. México: El Colegio de México.

Benjamin, W. (1935). Das Kunstwerk im Zeitalter seiner technischen Reproduzierbarkeit. Consultada la traducción española del original (2003). México: Ítaca.

Cerezo, A. (2017). Segundo de Chomón y el arte de un cine 'sin literatura', Hispanófila vol. 179, pp. 125-140.

Delgado Cruz, S. (2019). Arqueología de un mito. El acto del 12 de octubre de 1936 en el Paraninfo de la Universidad de Salamanca. Madrid: Sílex.

Dougherty, D. (2001). Pensándolo bien: el teatro a la luz del cine (1914-1936). Anales de la literatura española contemporánea vol. 26 (1), pp. 6-25.

Fernández Urbina, J. M. (1989). Unamuno y el cinematógrafo: no ver, sino verbo. Cuadernos del norte 55, pp. 78-83.

Garrido Ardila, J. A. (2012). Unamuno, el monólogo interior y el flujo de conciencia: de William James y "Amor y pedagogía" a Knut Hamsun y "Niebla". Hispanic Review vol. 80, $\mathrm{n}^{\circ} 3$, pp. 445-466.

$11 \mathrm{Al}$ respecto, la película de Amenábar no plasma el proceso actual de revisión historiográfica al que está siendo sometida su figura en relación con el enigmático episodio de su muerte. 
- (2013). Itinerario de la novela modernista española. Revista de Literatura vol. LXXV, ${ }^{\circ}$ 150, 547-571. DOI: 10.3989/revliteratura.2013.02.022

Gómez Mesa, L. (1978). La literatura española en el cine nacional 1909-1977. Madrid: Filmoteca Nacional Española.

González Requena, J. (2000). El ser de las imágenes. De la teoría al análisis de la imagen. Madrid: Universidad Complutense. Recuperado de https://gonzalezrequena.com/textos-en-linea-0-2/libros-en-linea/el-ser-de-las-imagenes/

Gullón, R. (1976). Autobiografías de Unamuno. Madrid: Gredos.

Marías, J. (1997). Miguel de Unamuno (3ª edición). Madrid: Espasa-Calpe.

Meyer, F. (1955). L'ontologie de Miguel de Unamuno. París: Presses Universitaires de France.

Migueláñez González, D. (2020). Unamuno y su «costumbre»: el tratamiento del amor en Mientras dure la guerra, de Alejandro Amenábar. Actio Nova: Revista de Teoría de la Literatura y Literatura comparada, monográfico 4, pp. 427-445.

Ouimette, V. (1976). Unamuno, Blasco Ibáñez and España con honra. Bulletin of Hispanic Studies vol. LIII (4), 1976, pp. 315-322. DOI: 10.1080/1475382762000353315

Rabaté, C. y J. C. (2018). En el torbellino. Unamuno en la Guerra Civil. Madrid: Marcial Pons.

Ribbans, G. (1989). Dialéctica de lucha y ambigüedad en la novelística unamuniana. En D. Gómez Morella (Ed.), Actas del Congreso Internacional del Cincuentenario de Unamuno (pp. 153164). Salamanca: Universidad.

Roberts, S. G. (2007). Miguel de Unamuno o la creación del intelectual español moderno. Salamanca: Universidad.

Sandoval Ullán, A. (2004). El concepto de mujer en el pensamiento de Miguel de Unamuno. Cuadernos Cátedra Miguel de Unamuno 39, pp. 27-60.

Sulbarán, E. y Cruzco, D. (2018). Muerte, cine y representaciones semióticas en el film "Abre los ojos" (1997). Revista cbilena de semiótica 9, pp. 46-63.

Unamuno, M. (1909). Materialismo popular. Mi religión y otros ensayos breves. Consultada la edición compilatoria de 1964. Madrid: Espasa-Calpe.

- (1914). Niebla. Madrid: Renacimiento.

— (8 de abril de 1916). Tuvo un gesto... La Esfera. 
- (19 de septiembre de 1919). Caleidoscopio cinematográfico. Nuevo Mundo.

— (5 de noviembre de 1920). El hombre espejo. Nuevo Mundo.

- (28 de abril de 1922). Los mozos del partido. Nuevo Mundo.

- (29 de abril de 1923). La literatura y el cine. La Nación.

- (1931). Agonía del cristianismo. Madrid: Renacimiento.

— (16 de septiembre de 1932). Juventud, milagro y misterio. El Sol.

- (25 de noviembre de 1934). En torno al sex-appeal. Ahora.

— (17 de marzo de 1936). Cine sonoro revolucionario. Ahora.

— (1959). Teatro completo. Edición de M. García Blanco. Madrid: Aguilar.

— (1966). Obras completas, t. VII. Edición de M. García Blanco. Madrid: Escélicer.

Utrera, R. (1982). Modernismo y 98 frente a Cinematógrafo. Sevilla: Universidad.

Yuste, J. (2019, 27 de septiembre). Alejandro Amenábar: "Hacer una película como 'Mientras dure la guerra' es un acto de fe". El Cultural. Recuperado de https://elcultural.com/ alejandro-amenabar-hacer-una-pelicula-como-mientras-dure-la-guerra-es-un-acto-de-fe 
MHJournal Vol. 12 (2) | Año 2021 - Artículo no 14 (181) - Páginas 291 a 310 - mhjournal.org

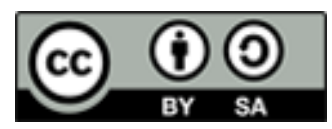

Licencia Creative Commons

Miguel Hernández Communication Journal

mhjournal.org

\section{Cómo citar este texto:}

Javier González Torres (2021): La mirada de Alejandro Amenábar sobre un enemigo acérrimo: ¿la reconciliación del cine con Miguel de Unamuno?, en Miguel Hernández Communication Journal, Vol. 12 (2), pp. 291 a 310. Universidad Miguel Hernández, UMH (Elche-Alicante). DOI: 10.21134/mhjournal.v12i.1337 